\title{
Usulan Perancangan Alat Bantu Untuk Meminimalisir Kelelahan Fisik dan Mental Pekerja
}

\author{
Ferida Yuamita ${ }^{1}$, Retno Arum Sary ${ }^{2}$
}

\begin{abstract}
CV Poetra Mandiri Karton is a company that has not been able to meet production target each day. Based on preliminary analysis, production underproduction was due to workers' fatigue caused by manual material handling activities in the entire production process. To solve these problems, nordic body map (NBM) approach was applied. Prior to work, workers experienced musculoskeletal fatigue at down waist, and they experienced musculoskeletal fatigue at up waist, left forearm, right forearm, left hand, right hand, left ankle, and right ankle after work. Based on questionnaire of National Aeronautics and Space Administration Task Load Index (NASA-TLX), average of mental workload from all three groups is quite heavy. By using rapid entire body assessment (REBA), it is found that average value of the risk in group 1 and group 2 requires immediate action, whereas action is required by the third group. This article also presents a trolley design that will be used in manual material handling activities.
\end{abstract}

Keywords.Manual Material Handling, Nordic Body Map, NASA-TLX, REBA, design, trolley

\begin{abstract}
Abstrak. CV Poetra Mandiri Karton merupakan perusahaan yang belum dapat memenuhi target produksi karton pada setiap harinya. Berdasarkan analisis awal, jumlah produksi tidak tercapaikarenatingkat kelelahan pekerja karena aktivitas manual material handling pada seluruh proses produksinya. Penyelesaian permasalahan tersebut dengan pendekatan kuesioner nordic body map (NBM). Pekerja mengalami kelelahan muskuloskeletal sebelum melakukan pekerjaan pada bagian pinggang bawah. Setelah melakukan pekerjaan, pekerja mengalaminya pada pinggang atas, lengan bawah kiri, lengan bawah kanan, tangan kiri, tangan kanan, pergelangan kaki kiri, serta pergelangan kaki kanan. Berdasarkan kuesioner National Aeronautics and Space Administration Task Load Index (NASA-TLX), rata-rata beban kerja mental dari ke tiga grup tergolong agak berat. Berdasarkan rapid entire body assessment (REBA), rata-rata nilai resiko pada grup 1 dan 2 memerlukan tindakan secepatnya dan pada grup 3 memerlukan tindakan. Artikel ini juga menampilkan desain trolley yang akan digunakan dalam aktivitas manual material handling.
\end{abstract}

Kata kunci.Manual Material Handling, Nordic Body Map, NASA-TLX, REBA, desain, trolley

\section{Pendahuluan}

CV. Poetra Mandiri Karton merupakan perusahaan yang memproduksi karton dengan bahan baku kertas bekas, bubur kertas, dan serbuk kayu yang keseluruhannya merupakan bahan sisa

\footnotetext{
${ }^{1}$ Ferida Yuamita, Jurusan Teknik Industri, Universitas Teknologi Yogyakarta. J1. Ringroad Utara, Jombor, Sleman, Yogyakarta, 55285 (email: feridayuamita@gmail.com)

2 Retno Arum Sary, Jurusan Teknik Industri, Universitas Teknologi Yogyakarta. J1. Ringroad Utara, Jombor, Sleman, Yogyakarta, 55285 (email: sariretnoarum@gmail.com)
}

Diajukan: 31-06-2016

Diperbaiki: 1-12-2016 yang tidak terpakai dari percetakan dan perusahaan lain. Saat ini perusahaan telah memiliki banyak pelanggan, namun tidak diimbangi dengan pemenuhan target produksi karton pada setiap harinya. Target minimal produksi karton adalah $50 \mathrm{pack} / \mathrm{hari} / \mathrm{grup}$. Rata-rata produksi karton pada 2 bulan terakhir adalah $36 \mathrm{pack} / \mathrm{hari} / \mathrm{grup}$. Tingkat produksi yang tidak terpenuhi rata-rata sebanyak 14 pack/hari/grup.

Untuk melihat ketercapaian hasil produksi dilakukan pengamatan awal terhadap 3 grup pekerja. Grup 1 dapat memproduksi rata-rata 40 pack/hari/grup. Grup 2 dan grup 3 dapat memproduksi rata-rata 43 pack/hari/grup dan 36 pack/hari/grup. Hasil pengamatan awal tersebut menunjukkan target produksi tidak tercapai. Berdasarkan identifikasi masalah dengan fishbone diagram dapat diketahui bahwa penyebab dari 
permasalahan tersebut adalah kelelahan yang dialami oleh pekerja akibat manual material handling pada seluruh proses produksinya. Hal itu sesuai dengan pernyataan Byrd dan Moore (1986) tentang indikator kelelahan, yaitu penurunan produktivitas kerja pada pekerja terutama oleh adanya kelelahan kerja.

Savitri, dkk. (2012) melakukan evaluasi postur kerja untuk mengurangi resiko kelelahan akibat beban kerja fisik. Sedangkan Akyeampong, dkk. (2014) melakukan perancangan alat untuk mengurangi resiko kelelahan akibat beban kerja mental. Artikel ini menggunakan kedua penelitian tersebut sebagai pendekatan dalam penyelesaian permasalahan, yaitu menggunakan metode nordic body map (NBM), rapid entire body assessment (REBA), dan National Aeronautics and Space Administration task load index (NASA-TLX) dalam melakukan evaluasi postur kerja dan perancangan alat bantu manual material handling (MMH) berupa trolley.

Perbedaan penelitian ini dengan kedua penelitian tersebut adalah penelitian ini mencakup kelelahan fisik dan mental pekerja akibat manual material handling. Penelitian sebelumnya hanya memfokuskan pada salah satu kelelahan pekerja yang berkaitan dengan masalah yang diteliti. Penelitian ini perlu dilakukan untuk mengetahui kondisi kelelahan muskuloskeletal pekerja, apabila diukur dengan kuesioner NBM, mengetahui kondisi kelelahan mental pekerja apabila diukur dengan kuesioner NASA-TLX, mengetahui penilaian aktivitas pekerja berdasarkan postur dan pergerakan kerja dengan REBA, dan mengusulkan perancangan alat bantu dan evaluasi postur kerja guna meminimalisir tingkat kelelahan pekerja

Penanganan material secara manual memiliki beberapa keuntungan (Suhardi, 2008). Salah satunya adalah fleksibel dalam gerakan, sehingga memberikan kemudahan pemindahan beban pada ruang terbatas dan pekerjaan yang tidak beraturan untuk beban ringan akan lebih murah, bila dibandingkan menggunakan mesin. Tidak semua material dapat dipindahkan dengan alat. Walaupun demikian, aktivitas MMH yang tidak tepat dapat menimbulkan kerugian bahkan kecelakaan pada karyawan. Tingginya tingkat cidera atau kecelakaan kerja selain merugikan secara langsung yaitu sakit yang diderita oleh pekerja, kecelakaan tersebut juga akan berdampak buruk terhadap kinerja perusahaan yaitu berupa penurunan produktivitas perusahaan, baik melalui beban biaya pengobatan yang cukup tinggi dan juga ketidakhadiran pekerja serta penurunan dalam kualitas kerja (Muslimah, dkk., 2006).

Salah satu metode untuk mengetahui kelelahan musculoskeletal disease (MSDs) adalah dengan menggunakan kuesioner Nordic Body Map (NBM). NBM membagi tubuh menjadi nomor 0 sampai 27 dari leher hingga kaki yang akan mengestimasi tingkat keluhan MSDs yang dialami pekerja. Kuesioner Nordic merupakan kuesioner yang paling sering digunakan untuk mengetahui ketidaknyamanan atau kesakitan pada tubuh. Responden yang mengisi kuesioner diminta untuk memberikan tanda ada tidaknya gangguan pada bagian area tubuh tersebut (Kroemer \& Grandjean, 1997).

Langkah pengukuran menggunakan NASATLX sebagai berikut (Hart \& Steaveland, 1988):

1. Pembobotan, dimana pekerja diminta untuk membandingkan dua dimensi yang berbeda dengan metode perbandingan berpasangan untuk keseluruhan dimensi (6 dimensi), yaitu 15 perbandingan berpasangan. Jumlah tally untuk tiap dimensi menjadi bobot dimensi.

2. Pemberian rating, dimana pekerja diminta memberikan penilaian/rating terhadap keenam dimensi beban mental.

Mengacu pada Persamaan 1, skor akhir beban mental NASA-TLX diperoleh dengan mengalikan bobot dengan rating setiap dimensi, kemudian dibagi dengan 15 .

Rerata beban kerja mental $=\frac{\text { Bobot } \times \text { Rating }}{15}$

Penilaian postur dan pergerakan kerja menggunakan metode REBA melalui tahapantahapan sebagai berikut (Higgnet dan Atamney, 2000):

Pengambilan data postur pekerja dengan menggunakan bantuan video atau foto untuk mendapatkan data postur tubuh secara detail.

1. Skor postur menggunakan lembar penilaian dan skor bagian tubuh. Perhitungannya dibagi dua kelompok. Kelompok A meliputi batang tubuh, leher, dan kaki, setelah dilakukan penilaian dimasukkan ke dalam tabel A. Kelompok B meliputi lengan atas, lengan bawah, dan pergelangan tangan. Postur 
kelompok B dinilai secara terpisah untuk sisi kiri dan kanan, setelah dilakukan penilaian dimasukkan ke dalam tabel B. Poin tambahan dapat ditambahkan atau dikurangi, tergantung pada posisinya. Proses ini dapat diulang untuk setiap sisi tubuh dan untuk postur lainnya.

2. Proses skor dengan tabel A untuk menghasilkan skor tunggal dari batang tubuh, leher, dan kaki. Skor ini dicatat dalam kotak pada lembar penilaian dan ditambahkan ke skor beban untuk memberikan skor A. Demikian pula lengan atas, lengan bawah, pergelangan tangan dengan tabel $\mathrm{B}$ untuk menghasilkan skor tunggal. Skor ini diulang jika resiko muskuloskeletal kanan dan kiri berbeda. Skor tersebut kemudian ditambahkan ke nilai kopling untuk menghasilkan skor B. A dan B dimasukkan ke dalam tabel $\mathrm{C}$ dan skor tunggal ini adalah skor C.

3. Menetapkan nilai REBA dengan menjumlah skor kegiatan untuk memberikan skor akhir REBA.
4. Menginformasikan tingkat tindakan sesuai dengan urgensi untuk tindakan pengendalian.

\section{Metodologi}

Objek pada penelitian ini adalah seluruh pekerja pada bagian produksi di CV. Poetra Mandiri Karton yang berjumlah 9 orang pekerja. Pekerja pada bagian produksi tersebut terbagi ke dalam 3 grup yang masing-masing terdiri dari 2 orang pekerja yang mengoperasikan alat cetak karton dan 1 orang pekerja yang menangani bubur karton dan pemindahan karton basah. Alat yang digunakan dalam penelitian ini adalah video recorder untuk merekam aktivitas pekerja, meteran untuk mengukur antropometri pekerja, dan busur untuk mengukur sudut perputaran tubuh pekerja.

Tahap awal pada penelitian ini adalah melakukan identifikasi masalah dengan mencatat hasil produksi dan menganalisis ketercapaian target produksi. Hasil identifikasi masalah dapat dilihat pada Gambar 1 dan Gambar 2.

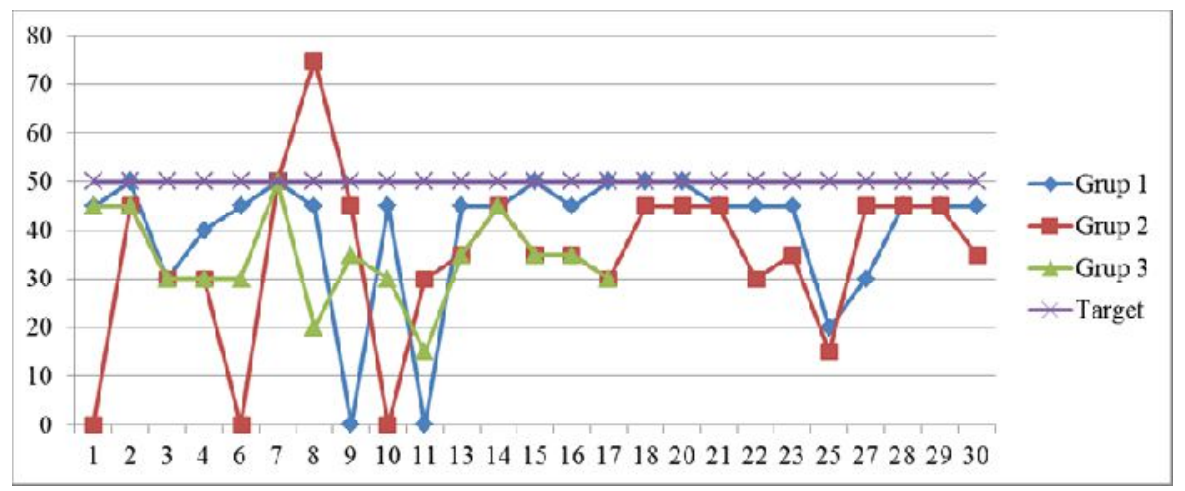

Gambar 1. Grafik pemenuhan target produksi pada bulan Agustus (Sumber: CV Poetra Mandiri Karton, 2015)

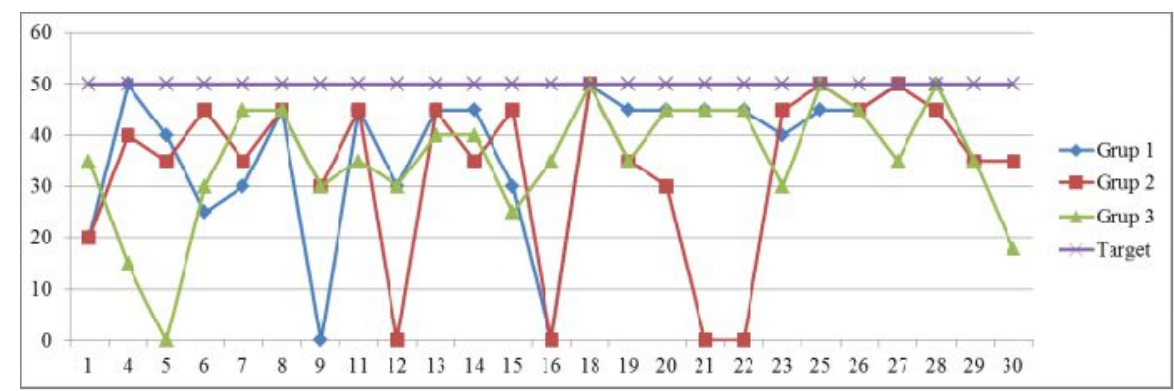

Gambar 2. Grafik pemenuhan target produksi bulan September (Sumber: CV Poetra Mandiri Karton, 2015) 


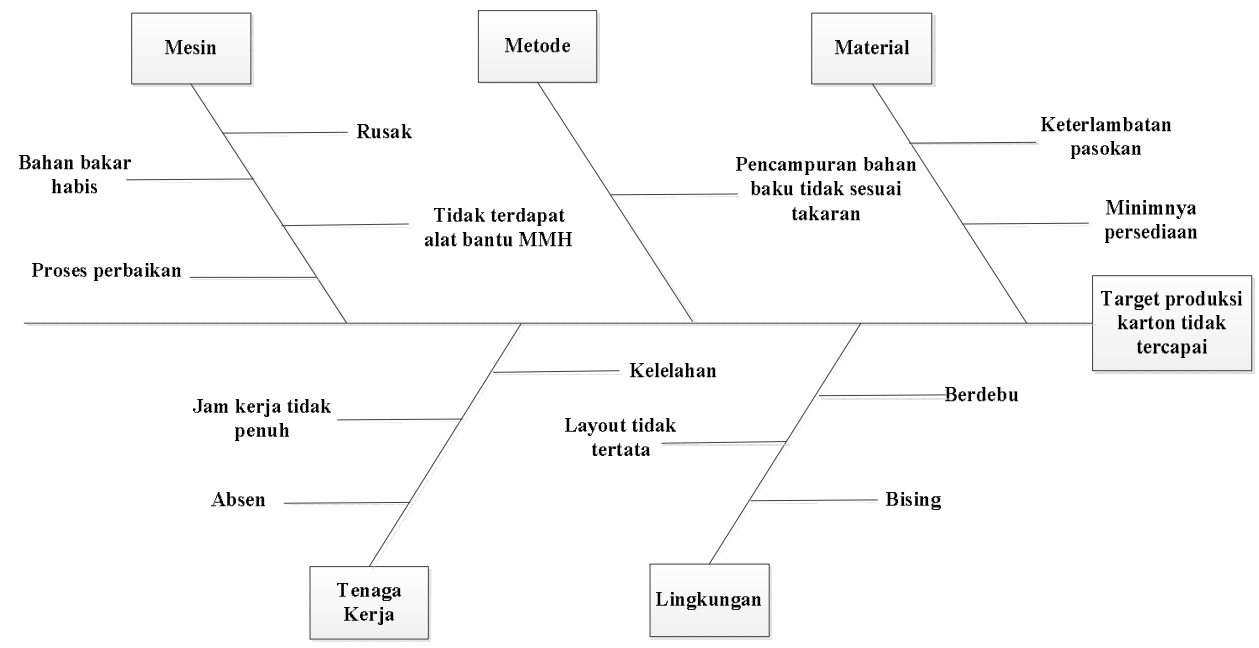

Gambar 3. Fishbone diagram

Target minimal produksi karton adalah 50 pack/hari/grup, sedangkan rata-rata produksi karton pada bulan Agustus dan September 2016 adalah $36 \mathrm{pack} /$ hari/grup maka banyak produk yang tidak dapat diproduksi disetiap grup adalah 14 pack/hari. Sedangkan rata-rata grup 1 dapat memproduksi $40 \mathrm{pack} / \mathrm{hari} / \mathrm{grup}$, grup 2 dapat memproduksi 43 pack/hari/grup, dan grup 3 dapat memproduksi $36 \mathrm{pack} / \mathrm{hari} / \mathrm{grup}$. Selanjutnya hasil identifikasi awal coba ditindak lanjuti dengan mencari akar penyebab permasalahan dengan menggunakan fishbone diagram pada Gambar 3.

Gambar 5 menunjukkan bahwa terdapat 5 faktor yang diindikasikan menjadi penyebab dari tidak terpenuhinya target produksi karton. Selanjutnya dilakukan pengkajian melalui wawancara dengan kepala produksi dan karyawan produksi untuk menemukan akar permasalahan yang terjadi. Berdasarkan hasil pengkajian tersebut dapat diketahui bahwa akar permasalahan dari pencapaian target produksi karton yang tidak tercapai yaitu kelelahan. Menurut Byrd dan Moore (1986) penurunan produktivitas kerja pada pekerja terutama oleh adanya kelelahan kerja. Berdasarkan hasil identifikasi masalah diatas, penulis mengusulkan untuk melakukan perancangan trolley sebagai alat bantu dalam aktivitas manual material handling. Tahap perancangan yang dilakukan dalam penelitian ini adalah:

1. Wawancara untuk mendapatkan karakteristik yang diinginkan responden

2. Menterjemahkan keinginan responden kedalam desain

3. Melakukan pengukuran antropometri

4. Melakukan pengukuran desain berdasar data antropometri

\section{HASIL DAN PEMBAHASAN}

Pengukuran keluhan pekerja dengan kuesioner NBM digunakan untuk mengetahui kelelahan muskuloskeletal pekerja yang nantinya akan dijadikan pertimbangan untuk perbaikan. Sugiharto, dkk. (2013) menggolongkan kelelahan muskuloskeletal yang paling sering muncul pada presentase $\geq 50 \%$. Kuesioner ini diberikan sebelum dan setelah melakukan pekerjaan (Corlet, 1992). Dengan melihat dan menganalisis peta tubuh (NBM), maka dapat diestimasi jenis dan tingkat keluhan otot skeletal yang dirasakan pekerja (Tarwaka, dkk., 2004). Hasil dari kuesioner NBM ditunjukkan pada Tabel 1 dan Tabel 2.

Berdasarkan tabel tersebut diperoleh bahwa kelelahan muskuloskeletal yang paling sering muncul sebelum melakukan pekerjaan adalah pada bagian pinggang bawah $55,56 \%$ yang disebabkan oleh kelelahan pada pekerjaan sebelumnya yang belum hilang. Sedangkan setelah melakukan pekerjaan adalah pada bagian pinggang bawah $55,56 \%$, pinggang atas $66,67 \%$, lengan bawah kiri $66,67 \%$, lengan bawah kanan 
Tabel 1. Rekap data kuesioner NBM sebelum melakukan pekerjaan

\begin{tabular}{|c|c|c|c|}
\hline No & Bagian Tubuh & $\begin{array}{c}\text { Jumlah } \\
\text { Keluhan } \\
\text { Sakit } \\
\end{array}$ & $\begin{array}{c}\text { Presentase } \\
\text { Keluhan } \\
\text { Sakit (\%) }\end{array}$ \\
\hline 0 & Leher Atas & 0 & 0,00 \\
\hline 1 & Leher Bawah & 1 & 11,11 \\
\hline 2 & Bahu Kiri & 0 & 0,00 \\
\hline 3 & Bahu Kanan & 0 & 0,00 \\
\hline 4 & Lengan Atas Kiri & 0 & 0,00 \\
\hline 5 & Punggung & 1 & 11,11 \\
\hline 6 & Lengan Atas Kanan & 1 & 11,11 \\
\hline 7 & Pinggang Atas & 3 & 33,33 \\
\hline 8 & Pinggang Bawah & 5 & 55,56 \\
\hline 9 & Pantat & 0 & 0,00 \\
\hline 10 & Siku Kiri & 0 & 0,00 \\
\hline 11 & Siku Kanan & 0 & 0,00 \\
\hline 12 & Lengan Bawah Kiri & 0 & 0,00 \\
\hline 13 & Lengan Bawah Kanan & 1 & 11,11 \\
\hline 15 & Pergelangan Tangan Kanan & 0 & 0,00 \\
\hline 16 & Tangan Kiri & 0 & 0,00 \\
\hline 17 & Tangan Kanan & 4 & 44,44 \\
\hline 18 & Paha Kiri & 0 & 0,00 \\
\hline 19 & Paha Kanan & 0 & 0,00 \\
\hline 20 & Lutut Kiri & 0 & 0,00 \\
\hline 21 & Lutut Kanan & 0 & 0,00 \\
\hline 22 & Betis Kiri & 0 & 0,00 \\
\hline 23 & Betis Kanan & 0 & 0,00 \\
\hline 24 & Pergelangan Kaki Kiri & 0 & 0,00 \\
\hline 25 & Pergelangan kaki Kanan & 0 & 0,00 \\
\hline 26 & Kaki Kiri & 1 & 11,11 \\
\hline 27 & Kaki Kanan & 1 & 11,11 \\
\hline
\end{tabular}

$55,56 \%$, tangan kiri 55,56\%, tangan kanan $77,78 \%$, pergelangan kaki kiri 55,56\%, serta pergelangan kaki kanan 55,56\% yang disebabkan:

1. Pinggang bawah, yaitu pada saat berdiri lama ketika bekerja.

2. Pinggang atas, yaitu pada saat membungkuk ketika memindahkan karton basah.

3. Lengan bawah kiri, yaitu saat mengangkat beban beratyang mencapai $10 \mathrm{~kg}$.

4. Lengan bawah kanan, yaitu saat mengangkat beban berat yang mencapai $10 \mathrm{~kg}$.
Tabel 2. Rekap data kuesioner NBM setelah melakukan pekerjaan

\begin{tabular}{|c|c|c|c|}
\hline No & Bagian Tubuh & $\begin{array}{c}\text { Jumlah } \\
\text { Keluhan } \\
\text { Sakit }\end{array}$ & $\begin{array}{c}\text { Presentase } \\
\text { Keluhan } \\
\text { Sakit (\%) }\end{array}$ \\
\hline 0 & Leher Atas & 4 & 44,44 \\
\hline 1 & Leher Bawah & 4 & 44,44 \\
\hline 2 & Bahu Kiri & 3 & 33,33 \\
\hline 3 & Bahu Kanan & 2 & 22,22 \\
\hline 4 & Lengan Atas Kiri & 3 & 33,33 \\
\hline 5 & Punggung & 4 & 44,44 \\
\hline 6 & Lengan Atas Kanan & 2 & 22,22 \\
\hline 7 & Pinggang Atas & 6 & 66,67 \\
\hline 8 & Pinggang Bawah & 5 & 55,56 \\
\hline 9 & Pantat & 3 & 33,33 \\
\hline 10 & Siku Kiri & 2 & 22,22 \\
\hline 11 & Siku Kanan & 1 & 11,11 \\
\hline 12 & Lengan Bawah Kiri & 6 & 66,67 \\
\hline 13 & Lengan Bawah Kanan & 5 & 55,56 \\
\hline 15 & Pergelangan Tangan Kanan & 4 & 44,44 \\
\hline 16 & Tangan Kiri & 4 & 44,44 \\
\hline 17 & Tangan Kanan & 5 & 55,56 \\
\hline 18 & Paha Kiri & 7 & 77,78 \\
\hline 19 & Paha Kanan & 4 & 44,44 \\
\hline 20 & Lutut Kiri & 5 & 44,44 \\
\hline 21 & Lutut Kanan & 2 & 22,22 \\
\hline 22 & Betis Kiri & 4 & 44,44 \\
\hline 23 & Betis Kanan & 3 & 33,33 \\
\hline 24 & Pergelangan Kaki Kiri & 5 & 55,56 \\
\hline 25 & Pergelangan kaki Kanan & 5 & 55,56 \\
\hline 26 & Kaki Kiri & 4 & 44,44 \\
\hline 27 & Kaki Kanan & 4 & 44,44 \\
\hline
\end{tabular}

5. Tangan kiri, yaitu pada saat melakukan gerakan secaraterus-menerusyang dilakukan secara manual dengan tangan.

6. Tangan kanan, yaitu pada saat melakukan gerakan secara terus-menerus yang dilakukan secara manual dengan tangan.

7. Pergelangan kaki kiri, yaitu pada saat berdiri lama ketika bekerja.

8. Pergelangan kaki kanan, yaitu pada saat berdiri lama ketika bekerja.

Hasil perhitungan skor rata-rata beban kerja

Tabel 3. Hasil jumlah tally kuesioner NASA-TLX

\begin{tabular}{lccccccccc}
\hline \multicolumn{1}{c}{ Faktor } & \multicolumn{3}{c}{ Grup 1 } & \multicolumn{3}{c}{ Grup 2 } & \multicolumn{3}{c}{ Grup 3 } \\
& P1 & P2 & P3 & P1 & P2 & P3 & P1 & P2 & P3 \\
\hline Mental Demand & 1 & 1 & 1 & 1 & 1 & 2 & 1 & 0 & 1 \\
Physical Demand & 3 & 3 & 3 & 3 & 3 & 5 & 4 & 3 & 4 \\
Temporal Demand & 3 & 4 & 3 & 1 & 0 & 2 & 1 & 3 & 4 \\
Performance & 2 & 2 & 0 & 3 & 4 & 0 & 3 & 3 & 1 \\
Effort & 4 & 1 & 5 & 3 & 4 & 4 & 5 & 4 & 3 \\
Frustration & 2 & 4 & 3 & 4 & 3 & 2 & 1 & 2 & 2 \\
Total & $\mathbf{1 5}$ & $\mathbf{1 5}$ & $\mathbf{1 5}$ & $\mathbf{1 5}$ & $\mathbf{1 5}$ & $\mathbf{1 5}$ & $\mathbf{1 5}$ & $\mathbf{1 5}$ & $\mathbf{1 5}$ \\
\hline
\end{tabular}


Tabel 4. Hasil rating scale

\begin{tabular}{lccccccccc}
\hline \multicolumn{1}{c}{ Faktor } & \multicolumn{3}{c}{ Grup 1 } & \multicolumn{3}{c}{ Grup 2 } & \multicolumn{3}{c}{ Grup 3 } \\
& P1 & P2 & P3 & P1 & P2 & P3 & P1 & P2 & P3 \\
\hline Mental Demand & 80 & 80 & 95 & 75 & 80 & 90 & 85 & 70 & 95 \\
Physical Demand & 90 & 90 & 95 & 95 & 90 & 90 & 95 & 80 & 95 \\
Temporal Demand & 70 & 70 & 90 & 65 & 85 & 80 & 75 & 80 & 90 \\
Performance & 80 & 40 & 80 & 80 & 80 & 60 & 55 & 55 & 40 \\
Effort & 80 & 70 & 80 & 75 & 85 & 90 & 75 & 70 & 85 \\
Frustration & 60 & 90 & 95 & 60 & 75 & 90 & 70 & 80 & 90 \\
\hline
\end{tabular}

Tabel 5. Hasil perhitungan rata-rata beban kerja mental pekerja

\begin{tabular}{|c|c|c|c|c|c|c|c|c|c|c|c|}
\hline \multirow{2}{*}{ Faktor } & \multicolumn{3}{|c|}{ Grup 1} & \multicolumn{3}{|c|}{ Grup 2} & \multicolumn{3}{|c|}{ Grup 3} & \multirow{2}{*}{ Total } & \multirow{2}{*}{ Skor } \\
\hline & P1 & P2 & P3 & P1 & P2 & P3 & P1 & P2 & P3 & & \\
\hline Mental Demand & 80 & 80 & 95 & 75 & 80 & 180 & 85 & 0 & 95 & 770 & 51 \\
\hline Physical Demand & 270 & 270 & 285 & 285 & 270 & 450 & 380 & 240 & 380 & 2830 & 188,7 \\
\hline Temporal Demand & 210 & 280 & 270 & 65 & 0 & 160 & 75 & 240 & 360 & 1660 & 110,7 \\
\hline Performance & 160 & 80 & 0 & 240 & 320 & 0 & 165 & 165 & 40 & 1170 & 78 \\
\hline Effort & 320 & 70 & 400 & 225 & 340 & 360 & 375 & 280 & 255 & 2625 & 175 \\
\hline Frustration & 120 & 360 & 285 & 240 & 225 & 180 & 70 & 160 & 180 & 1820 & 121 \\
\hline Total & 1160 & 1140 & 1335 & 1130 & 1235 & 1330 & 1150 & 1085 & 1310 & & \\
\hline Skor & 77,3 & 76 & 89 & 75,3 & 82,3 & $\mathbf{8 8 , 7}$ & 76,7 & 72,3 & 87,3 & & \\
\hline
\end{tabular}

mental pekerja berdasarkan kuesioner NASA-TLX pada Tabel 3 yang diperoleh berdasarkan Pers.[1].

Jumlah tally tersebut diperoleh berdasarkan jumlah dari masing-masing dimensi yang telah dilingkari oleh pekerja. Jumlah tally ini kemudian menjadi bobot untuk tiap indikator beban mental seperti yang ditunjukkan pada Tabel 4.

Mengacu pada Tabel 5 yakni hasil perhitungan rerata beban mental pekerja maka hasilnya adalah 80,6 yang tergolong agak berat. Sedangkan rerata beban kerja mental grup 1 adalah 80,8 dan grup 2 adalah 82,1 yang tergolong agak berat, dan grup 3 adalah 78,8 yang tergolong sedang. Berdasarkan hasil tersebut dapat dikatakan bahwa grup 1 dan 2 mengalami beban kerja mental yang melebihi rata-ratanya sedangkan grup 3 adalah sebaliknya. Dengan demikian beban kerja mental yang dialami oleh ketiga grup tersebut juga tidak seimbang yang disebabkan oleh pekerjaan itu sendiri.

Apabila dihitung rata-rata dimesi beban kerja mental yang dirasakan oleh ketiga grup tersebut maka diperoleh bahwa beban kerja mental paling banyak disebabkan oleh physical demand sebesar 188,7, effort sebesar 175, frustration sebesar 121 , temporal demand sebesar 110,7, performance sebesar 78, dan mental demand sebesar 51. Dengan demikian munculnya beban kerja mental yang dirasakan oleh pekerja paling banyak disebabkan oleh adanya aktivitas fisik yang melebihi kemampuan pekerja.

Penilaian aktivitas pekerja dengan REBA assessment worksheet dilakukan berdasarkan rekaman video aktivitas pekerja. Untuk mempermudah dalam menganalisis maka rekaman video tersebut dipause sesuai kebutuhan yaitu pada saat pekerja mengangkat karton dari mesin cetak, pekerja membawa karton ke lokasi penampungan sementara, dan pekerja meletakkan karton di lokasi penampungan sementara, seperti ditunjukkan pada Gambar 3 sampai Gambar 5.

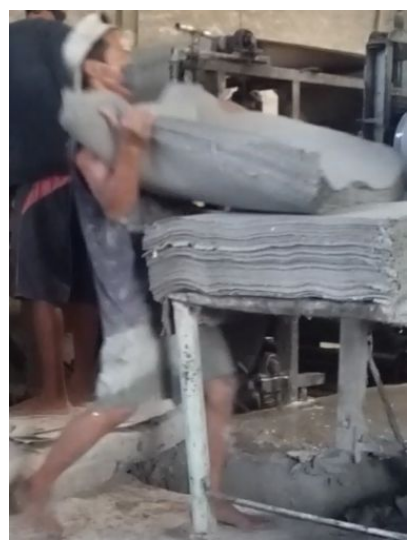

Gambar 3. Pekerja 3 grup 1 mengangkat karton dari mesin cetak 


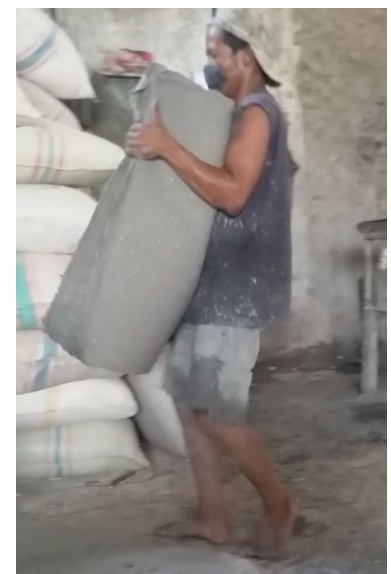

Gambar 4. Pekerja 3 grup 1 membawa karton ke lokasi penampungan sementara

Pada aktivitas pemindahan karton yang terdapat pada Gambar 3, Gambar 4, dan Gambar 5 menunjukkan bahwa beberapa elemen pekerjaan yang harus dikerjakan oleh pekerja yaitu pekerja mengangkat karton dari alat cetak, pekerja membawa karton ke lokasi penampungan sementara dan pekerja meletakkan karton di lokasi penampungan sementara. Untuk mendapatakan nilai beban kerja dilakukan analisis dengan menggunakan REBA seperti pada Tabel 4.

Tabel 5 menunjukkan hasil dari penilaian REBA assessment worksheet, bahwa rerata skor pada pekerja 3 grup 1 adalah 9 yang berarti memerlukan tindakan secepatnya. Tabel 6 menunjukkan rerata skor pada pekerja 3 grup 2 adalah 9 yang berarti memerlukan tindakan secepatnya. Tabel 7 menunjukkan rerata skor pada

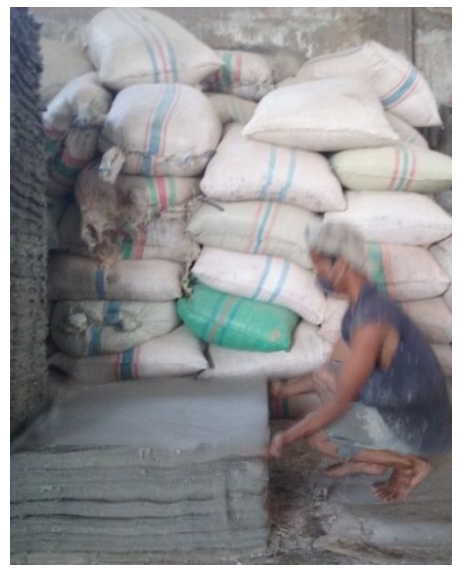

Gambar 5. Pekerja 3 grup 1 meletakkan karton di lokasi penampungan sementara

pekerja 3 grup 3 adalah 6 . Hal tersebut menunjukkan bahwa postur kerja memerlukan tindakan.

Hubungan antara kelelahan fisik, kelelahan mental, dan pencapaian target produksi yaitu, apabila melihat dari pencapaian target oleh ketiga grup tersebut, grup dengan rata-rata keluhan yang lebih besar merupakan grup dengan hasil produksi karton yang lebih besar pula. Dengan demikian maka adanya keluhan sakit yang dialami oleh pekerja mempengaruhi pencapaian target produksi karton. Selanjutnya grup dengan rata-rata beban kerja mental yang lebih besar merupakan grup dengan hasil produksi karton yang lebih besar pula. Beban kerja mental yang dialami oleh pekerja mempengaruhi pencapaian target produksi karton. Berdasarkan analisis

Tabel 4. Hasil penilaian REBA pekerja 3 grup 1

\begin{tabular}{|c|c|c|c|c|c|c|c|c|c|c|c|c|c|}
\hline \multirow[b]{3}{*}{ Aktivitas } & \multicolumn{13}{|c|}{ REBA Assessment Worksheet } \\
\hline & \multicolumn{3}{|c|}{ Nilai Tabel A } & \multirow[b]{2}{*}{ 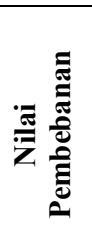 } & \multirow[b]{2}{*}{ 崩 } & \multicolumn{3}{|c|}{ Nilai Tabel B } & \multirow[b]{2}{*}{ 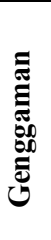 } & \multirow[b]{2}{*}{$\stackrel{\oplus}{\ddot{z}}$} & \multirow[b]{2}{*}{ 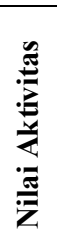 } & \multirow[b]{2}{*}{ } & \multirow[b]{2}{*}{ 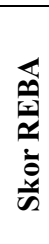 } \\
\hline & 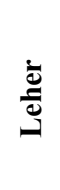 & 翌 & 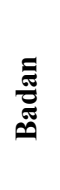 & & & 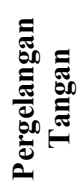 & 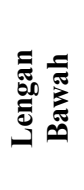 & 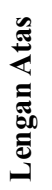 & & & & & \\
\hline Pekerja mengangkat karton dari alat cetak & 1 & 3 & 2 & 2 & 6 & 2 & 1 & 2 & 2 & 4 & 1 & 6 & 7 \\
\hline $\begin{array}{l}\text { Pekerja membawa karton ke lokasi } \\
\text { penampungan sementara }\end{array}$ & 2 & 3 & 2 & 2 & 7 & 2 & 1 & 2 & 2 & 4 & 1 & 8 & 9 \\
\hline $\begin{array}{l}\text { Pekerja meketakkan karton di lokasi } \\
\text { penampungan sementara }\end{array}$ & 2 & 4 & 2 & 2 & 8 & 2 & 1 & 2 & 2 & 4 & 1 & 9 & 10 \\
\hline \multicolumn{13}{|c|}{ Rata-Rata Skor REBA } & 9 \\
\hline
\end{tabular}


Tabel 5. Hasil penilaian REBA pekerja 3 grup 2

\begin{tabular}{|c|c|c|c|c|c|c|c|c|c|c|c|c|c|}
\hline \multirow[b]{3}{*}{ Aktivitas } & \multicolumn{13}{|c|}{ REBA Assessment Worksheet } \\
\hline & \multicolumn{3}{|c|}{$\begin{array}{c}\text { Nilai Tabel } \\
\text { A } \\
\end{array}$} & \multirow{2}{*}{ 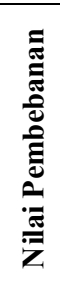 } & \multirow[b]{2}{*}{$\begin{array}{l}\varangle \\
\bar{z} \\
\bar{z}\end{array}$} & \multicolumn{3}{|c|}{$\begin{array}{c}\text { Nilai Tabel } \\
\text { B } \\
\end{array}$} & \multirow[b]{2}{*}{ 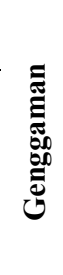 } & \multirow{2}{*}{$\stackrel{\infty}{\bar{E}}$} & \multirow{2}{*}{ 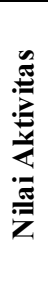 } & \multirow[b]{2}{*}{ 光 } & \multirow[b]{2}{*}{ 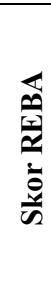 } \\
\hline & ¿্ঠ & 氧 & 莡 & & & 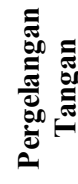 & 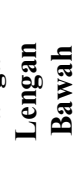 & 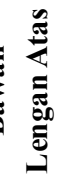 & & & & & \\
\hline Pekerja mengangkat karton dari alat cetak & 2 & 4 & 2 & 2 & 8 & 2 & 1 & 2 & 2 & 4 & 1 & 8 & 9 \\
\hline $\begin{array}{l}\text { Pekerja membawa karton ke lokasi penampungan } \\
\text { sementara }\end{array}$ & 2 & 3 & 2 & 2 & 7 & 1 & 1 & 1 & 2 & 3 & 1 & 8 & 9 \\
\hline $\begin{array}{l}\text { Pekerja meketakkan karton di lokasi penampungan } \\
\text { sementara }\end{array}$ & 2 & 3 & 2 & 2 & 7 & 1 & 1 & 1 & 2 & 3 & 1 & 8 & 9 \\
\hline
\end{tabular}

Tabel 6. Hasil penilaian REBA pekerja 3 grup 3

\begin{tabular}{|c|c|c|c|c|c|c|c|c|c|c|c|c|c|}
\hline \multirow[b]{3}{*}{ Aktivitas } & \multicolumn{13}{|c|}{ REBA Assessment Worksheet } \\
\hline & \multicolumn{3}{|c|}{$\begin{array}{c}\text { Nilai Tabel } \\
\text { A }\end{array}$} & \multirow{2}{*}{ 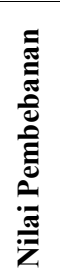 } & \multirow[b]{2}{*}{$\underset{\pi}{\pi}$} & \multicolumn{3}{|c|}{ Nilai Tabel B } & \multirow[b]{2}{*}{ 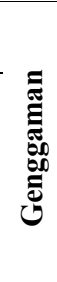 } & & \multirow[b]{2}{*}{ 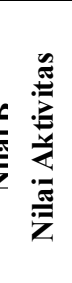 } & \multirow[b]{2}{*}{ } & \multirow[b]{2}{*}{ 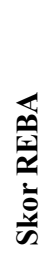 } \\
\hline & 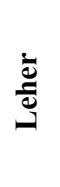 & 章 & $\underset{\tilde{E}}{\tilde{E}}$ & & & 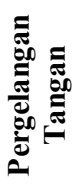 & ڤ & 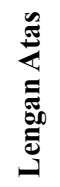 & & & & & \\
\hline \multirow{2}{*}{$\begin{array}{l}\text { Pekerja mengangkat karton dari alat cetak } \\
\text { Pekerja membawa karton ke lokasi penampungan } \\
\text { sementara }\end{array}$} & 1 & 3 & 2 & 2 & 6 & 1 & 1 & 2 & 2 & 3 & 1 & 6 & 7 \\
\hline & 2 & 3 & 2 & 2 & 5 & 1 & 1 & 1 & 2 & 1 & 1 & 4 & 5 \\
\hline $\begin{array}{l}\text { Pekerja meketakkan karton di lokasi penampungan } \\
\text { sementara }\end{array}$ & 1 & 3 & 3 & 2 & 7 & 1 & 1 & 2 & 2 & 1 & 1 & 4 & 5 \\
\hline
\end{tabular}

postur kerja dengan metode REBA, adanya postur kerja yang kurang tepat mempengaruhi pencapaian target produksi karton.

Adanya kelelahan fisik dan mental yang dialami pekerja disebabkan oleh pekerjaan yang dilakukan tanpa memperhatikan postur kerja. Adanya rolling pekerjaan yang tidak merata menyebabkan pembebanan pekerjaan juga tidak merata, dimana beban pekerjaan terpusat pada pekerja yang menangani pembuatan bubur dan pengangkatan karton basah. Terlebih karton basah yang diangkat tersebut relatif berat dan licin. Untuk itu diperlukan evaluasi dalam hal postur kerja dan perancangan alat bantu pemindahan karton basah yang dapat meminimalisir tingkat kelelahan fisik dan mental pekerja. Seperti yang dikemukakan Mas'idah, dkk. (2009) bahwa perlu mempertimbangkan pengadaan alat mekanis misalnya kereta dorong untuk meminimumkan resiko cidera tulang belakang (musculoskeletal disorder).

Keterkaitan antara kelelahan fisik, kelelahan mental, dan pencapaian target produksi yaitu, apabila pekerja mengalami kelelahan baik fisik maupun mental hal tersebut dapat mempengaruhi hasil produksi sehingga perusahaan tidak dapat mencapai targetnya. Untuk mengatasi masalah tersebut berdasarkan dari analisis kelelahan dengan NBM, NASA-TLX, dan REBA perlu dilakukan perancangan sebuah alat bantu, yakni trolley (Gambar 4).

Evaluasi postur kerja, baik pekerja dalam posisi berdiri, duduk atau sikap/posisi kerja yang lain, pertimbangan-pertimbangan ergonomis yang berkaitan dengan sikap/posisi kerja sangat penting (Wignjosoebroto, 2000). Dengan 
Tabel 7. Evaluasi postur kerja grup 1 pekerja 3

\begin{tabular}{|c|c|}
\hline Nama Aktivitas & Keterangan \\
\hline $\begin{array}{l}\text { Pekerja mengangkat karton dari } \\
\text { mesin cetak }\end{array}$ & $\begin{array}{l}\text { a. Posisi leher yang tegak lurus sudah benar. } \\
\text { b. Posisi kaki adalah menekuk dengan sudut antara } 30^{\circ} \text { - } \\
60^{\circ} \text {, seharusnya posisi kaki adalah tegak lurus. } \\
\text { c. Posisi badan adalah condong ke belakang pada sudut } \\
20^{0} \text {, seharusnya posisi badan adalah tegak lurus. } \\
\text { d. Berat karton basah yang diangkat }>10 \mathrm{~kg} \text {, seharusnya } \\
<10 \mathrm{~kg} \text {. } \\
\text { e. Gerakan pergelangan tangan dari posisi meletakkan } \\
\text { tangan ke beban sampai posisi mengangkat beban } \\
\text { adalah dari posisi lurus ke posisi menekuk ke atas pada } \\
\text { sudut } 15^{0} \text {, seharusnya posisi awalan adalah menekuk } \\
\text { ke bawah pada sudut } 15^{0} \text { dan posisi akhiran adalah } \\
\text { menekuk ke atas pada sudut } 15^{\circ} \text {. } \\
\text { f. Gerakan lengan bawah yang membentuk sudut antara } \\
60^{0}-100^{0} \text { ke atas sudah benar. } \\
\text { g. Gerakan lengan atas membentuk sudut antara } 20^{\circ}-45^{0} \\
\text { ke depan, seharusnya lengan atas tetap pada posisi } \\
\text { tegak lurus. } \\
\text { h. Kondisi genggaman adalah kurang baik karena sifat } \\
\text { karton basah yang lembek sehingga sulit digenggam, } \\
\text { seharusnya memakai sarung tangan kain. }\end{array}$ \\
\hline
\end{tabular}

Tabel 8. Hasil pengukuran antropometri pekerja

\begin{tabular}{rlrrr}
\hline Grup & InisialPekerja & TSB $(\mathrm{cm})$ & LB $(\mathrm{cm})$ & DG $(\mathrm{cm})$ \\
\hline \multirow{3}{*}{1} & Pekerja 1 & 109 & 38 & 4 \\
& Pekerja 2 & 98 & 39 & 4 \\
& Pekerja 3 & 98 & 41 & 3,5 \\
\hline \multirow{2}{*}{2} & Pekerja 1 & 101 & 40 & 4 \\
& Pekerja 2 & 99 & 42 & 3,5 \\
& Pekerja 3 & 106 & 42 & 4 \\
\hline \multirow{2}{*}{3} & Pekerja 1 & 97 & 39 & 3 \\
& Pekerja 2 & 98 & 39 & 4 \\
\cline { 2 - 5 } & Pekerja 3 & 101 & 42 & 3 \\
\hline \multicolumn{2}{l}{ Rata-rata } & $\mathbf{1 0 0 , 7 8}$ & $\mathbf{4 0 , 2 2}$ & $\mathbf{3 , 6 7}$ \\
\hline
\end{tabular}

demikian perbaikan postur kerja dapat dilakukan oleh pekerja yang mengoperasikan alat cetak dan pekerja yang menangani bubur karton dan pemindahan karton basah sebagai berikut (sesuai dengan Tabel 7):

1. Berdiri dengan posisi tegak, baik posisi kaki, badan, lengan atas, dan leher agar beban ditopang oleh seluruh anggota tubuh.

2. Menggunakan sarung tangan kain agar tangan pekerja terhindar dari resiko terkena sayatan benda tajam dan membantu pekerja dalam mengangkat karton basah agar tidak licin.

3. Melakukan gerakan gerakan relaksasi pada jam istirahat sehingga tubuh terasa lebih segar. Sebaiknya pekerja beristirahat tiap 5 menit setelah bekerja 30 menit untuk memulihkan kekuatan otot.

4. Pengurangan beban angkat menjadi $<10 \mathrm{~kg}$ agar tidak beresiko cidera.

Berikut hasil dari pengukuran dimensi tubuh pekerja yang digunakan untuk perancangan alat bantu manual material handling.

Pekerja memiliki ukuran di sekitar rataratanya sehingga rancangan alat bantu kerja akan didasarkan pada rata-rata ukuran. Hasil dari penetapan nilai ukuran tersebut adalah sebagai berikut:

1. Tinggi pegangan trolley (dimensi: tinggi siku berdiri (TSB), persentil: 50, perhitungan: $100,78 \mathrm{~cm})$. 


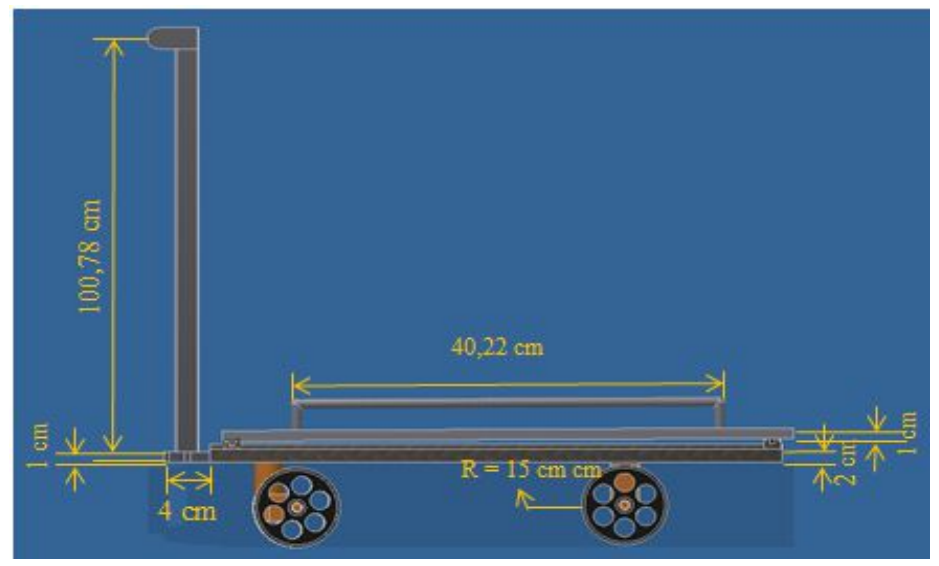

Gambar 4. Usulan rancangan trolley tampak samping

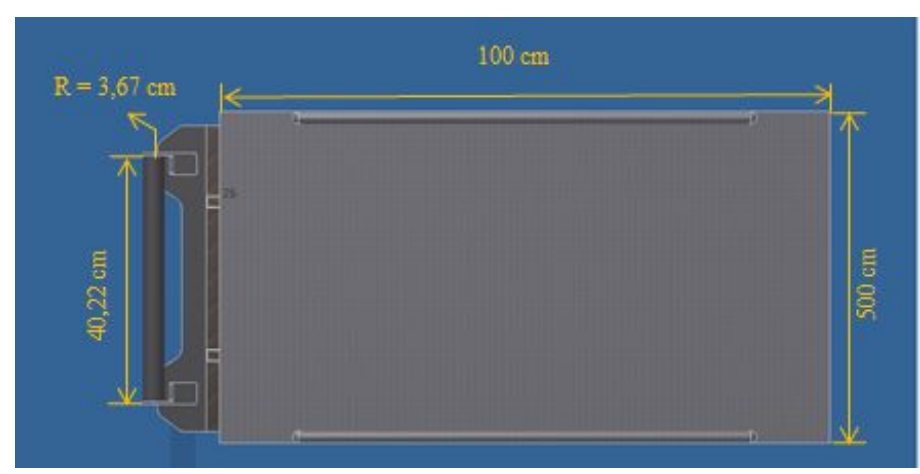

Gambar 5. Usulan rancangan trolley tampak atas

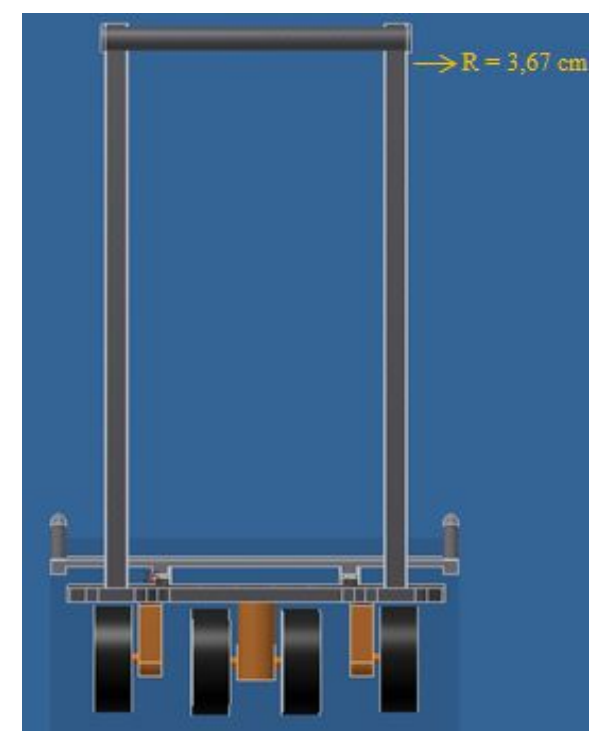

Gambar 6. Usulan rancangan trolley tampak depan

2. Lebar pegangan trolley (dimensi: lebar bahu (LB), persentil: 50, perhitungan: 40,22 cm).

3. Diameter pegangan trolley (dimensi: diameter genggam (DG), persentil: 50, perhitungan: $3,67 \mathrm{~cm})$.

Dengan menggunakan alat kerja yang telah 


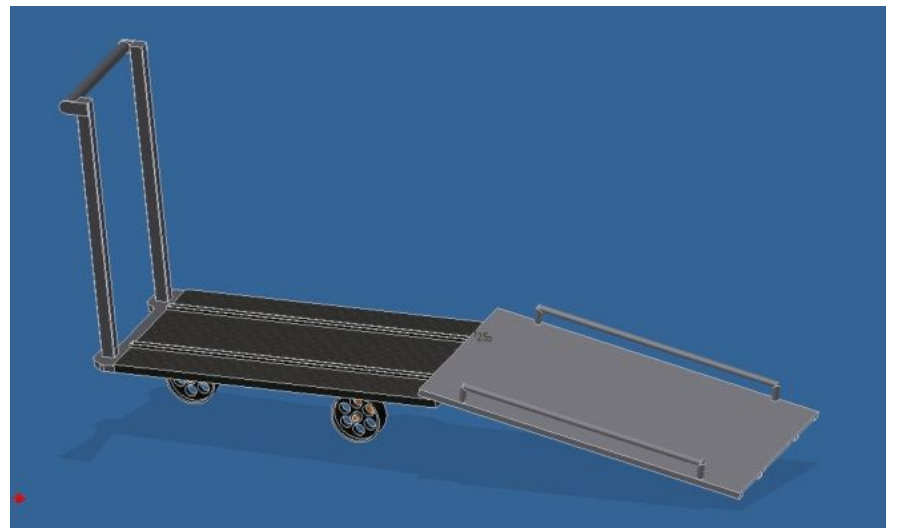

Gambar 7. Usulan rancangan trolley tampak 3 dimensi

dirancang, diharapkan terjadi perubahan sistem kerja pekerja. Adapun sistem kerja baru untuk aktivitas memindahkan karton basah dari alat cetak ke tempat penampungan sementara adalah sebagai berikut:

1. Pekerja mengambil trolley, kemudian membawanya ke alat cetak karton. Selanjutnya pekerja memindahkan karton basah dari alat cetak ke trolley.

2. Trolley didorong oleh pekerja ke tempat penampungan sementara.

3. Bidang miring pada trolley didorong ke bawah, kemudian kertas digeser di tempat penampungan sementara.

Apabila kapasitas angkut trolley tersebut adalah $100 \mathrm{~kg}$, sedangkan kemampuan pekerja dalam memindahkan karton basah adalah $15 \mathrm{~kg}$ untuk sekali angkat. Penggunaan trolley dapat mengurangi intensitas pemindahan sejumlah $85 \mathrm{~kg}$ atau 7 kali pemindahan ditambah dengan resiko kelelahan fisik dan mental pekerja. Dengan adanya peningkatan kapasitas angkut karton basah, maka jumlah karton basah yang dibawa ke proses penjemuran juga meningkat, sehingga karton yang akan diproses pada bagian finishing juga meningkat. Dengan demikian karton yang dapat diproduksi pada setiap harinya akan meningkat menurut estimasi sebagai berikut:

- waktu produksi/lembar $=8$ detik,

- waktu kerja efektif $=6$ jam $=21.600$ detik,

- isi pack = 35 lembar,

- rerata produksi $/$ hari $=2.700$ lembar,

- jumlah pack $=2.700 / 35=77$ pack $/$ hari.

Hal ini menunjukkan peningkatan tingkat produksi sebesar $113 \%$.

\section{SIMPULAN}

Postur kerja manual yang dilakukan saat ini terbukti menimbulkan resiko pada pekerja, khususnya pada penanganan material secara manual. Postur kerja untuk penanganan bahan baku kertas karton basah memerlukan tindakan secepatnya pada grup 2, dan memerlukan tindakan pada grup 3. Usulan perbaikan dapat dilakukan dengan perancangan alat kerja berupa trolley yang memungkinkan pekerja untuk memindahkan karton basah tanpa melakukan pengangkatan secara manual. Perbaikan postur kerja dan penggunaan sarung tangan kain juga dilakukan, agar beban ditopang oleh seluruh anggota tubuhdan pekerja terhindar dari resiko terkena kerja. Pekerja beristirahat tiap 5 menit setelah bekerja 30 menit untuk memulihkan kekuatan otot, dan pengurangan beban angkat menjadi $<10 \mathrm{~kg}$, agar tidak beresiko cidera. Langkah-langkah di atas dapat meningkatkan produksi.

\section{DAFTAR PUSTAKA}

Akyeampong, J.; Udoka, S.; Caruso, G.; Bordegoni, M. 2014. "Evaluation of hydraulic excavator humanmachine interface concepts using NASA-TLX". International Journal of Industrial Ergonomics, Vol. 44, pp. $374-382$.

Byrd,J.; Moore, L.T. 1986. Strategic Planning for Industrial Engineering Function. New York: Van Nostrand Reinhold Company.

Corlett, E.N. 1992. Evaluation of Human Work: A Practical Ergonomics Methodology. London: Taylor \& Francis. Inc.

Hart, S.G.; Staveland, L.E. 1988. Development of NASA-TLX (Task Load Index): Results of Empirical and Theoritical 
Research, Human Mental Workload. North Holland: Elsevier Science Publishers B.V.

Higgnet,S.; McAtamney,L. 2000. "Rapid entire body assesment (REBA)". Journal Applied Ergonomics, Vol.31 (2), pp. $201-205$.

Kroemer, K.H.E.; Grandjean, E. 1997. Fitting the Task to TheMan: ATextbook of Occupational Ergonomis. 5th ed. Philadelphia: Taylor \& Francis.

Mas'idah, E.; Fatmawati, W.; Ajibta, L. 2009.“Analisis manual material handling $(\mathrm{MMH})$ dengan mengunakan metode biomekanika untuk mengidentifikasi resiko cedera tulang belakang (mosculosketelal disorder) (Studi Kasus pada Buruh Pengangkat Beras di Pasar Jebor Demak)". Majalah Ilmiah Sultan Agung, Vol. 45(119), pp. 37-56.

Muslimah, E.; Pratiwi, I.; Rafsanjani, F. 2006. "Analisis Manual Material Handling Menggunakan NIOSH Equation".Jurnal Ilmiah Teknik Industri, Vol.5 (2), pp. $53-60$.

Savitri, A.; Mulyati, G.T.; Azis, I.W.F. 2012. "Evaluation of working postures at a garden maintenance service to reduce musculoskeletal disorder risk (A case study of PT. Dewijaya Agrigemilang Jakarta)". Agroindustrial Journal, Vol. 1 (1), pp. $21-27$.

Sugiharto, A.I.; Trihastuti, D.; Hartanti, L.P.S. 2013. "Analisis perbaikan postur dan metode kerja untuk mengurangi kelelahan muskuloskeletal di PT. XYZ Surabaya”. Jurnal Gema Aktualita, Vol.2(2), pp. 98 106.

Suhardi,B. 2008. Buku Perancangan Sistem Kerja dan Ergonomi. Jakarta: Direktorat Pembinaan Sekolah Menengah Kejuruan

Tarwaka, T.; Bakri, S.H.A.; Sudiajeng, L. 2004. Ergonomi untuk Keselamatan Kerja dan Produktivitas. Surakarta: UNIBA Press

Wignjosoebroto, S. 2000. Ergonomi Studi Gerak dan Waktu: Teknik Analisis untuk Peningkatan Produktivitas Kerja. Surabaya: Guna Widya 